\title{
PEMETAAN ZONA BIJIH EMAS EPITERMAL SULFIDASI RENDAH MENGGUNAKAN METODE RESISTIVITAS 2D DAN POLARISASI TERINDUKSI
}

\author{
Bimakurnia Septadi ${ }^{1)}$, Fakhriar Naufaldi ${ }^{1)}$, Fikrizan Andradit ${ }^{1)}$, Amien Widodo ${ }^{1)}$, Arief Ismanto $^{2)}$ \\ ${ }^{1}$ Departemen Teknik Geofisika, FTSLK, Institut Teknologi Sepuluh Nopember Surabaya (ITS) \\ ${ }^{2}$ PT GSM J-Resources Nusantara \\ e-mail: bimakurniaseptadi@gmail.com
}

\begin{abstract}
Abstrak. Prospek Biku merupakan salah satu wilayah di Gorontalo yang memiliki potensi mineral emas. Pemetaan geofisika menggunakan metode geolistrik resistivitas dan polarisasi terinduksi digunakan untuk mengetahui persebaran litologi yang ada di bawah permukaan. Hasil pemetaan dipermukaan menunjukkan Batuan Breksi hidrotermal dan intrusif riodasit dengan alterasi silika klorit-silika argilik mengandung mineralisasi emas yang tinggi. Resistivitas digunakan untuk mengetahui persebaran litologi sementara polarisasi terinduksi untuk melihat alterasi yang menyertainya. Berdasarkan hasil pengolahan data, litologi breksi hidrotermal memiliki nilai resistivitas antara $>150-250 \Omega$ m dengan nilai chargeability antara 4-8 ms yang teralterasi silika argilik. Litologi intrusif riodasit degan rentang nilai $>350 \Omega \mathrm{m}$ dan sering ditemukan kontak langsung dengan breksi hidrotermal dengan alterasi silika - silika klorit maupun silika argilik dengan nilai chargeability hingga 12 ms berasosiasi dengan patahan.
\end{abstract}

Kata Kunci: Mineral emas, resistivitas, polarisasi terinduksi, breksi hidrotermal, intrusif rodasit.

\begin{abstract}
The Biku's Prospect is one of the areas in Gorontalo where has potential gold mineral. The geological surface mapping show that lithology of the hydrothermal breccia and intrusive riodacite with silicic chlorite-silicic argilic alteration contain high gold mineralization. Geophysical mapping using geoelectrical resistivity and induced polarization methods was used to determine the spread of existing lithologies below the surface. Resistivity is used to determine the spread of lithology while polarization is induced to see the accompanying alterations. Based on the results of data processing, hydrothermal breccia has resistivity value between $\leq 150-250 \Omega m$ with chargeability value between 4-8 ms which is generally silica-argilic alteration. Intrusive riodacit with a range of values $\geq 350 \Omega m$ and frequent direct contact with hydrothermal breccias with silica-silica chlorite and silica-argilic alteration with a chargeability value of up to 12 ms assosiated with breccia fault.
\end{abstract}

Keywords: Gold mineralization, resistivity, induced polarization, hydrotermal breccia, intrusive rodacit.

\section{PENDAHULUAN}

Emas, sebagai salah satu komoditi tambang yang memegang peran penting dalam penerimaan devisa sekaligus menjaga stabilitas ekonomi negara memerlukan perhatian khusus sehingga kegiatan pencarian, pengolahan dan produksinya bisa terus berjalan. Potensi emas Indonesia dilihat dari sejarah memang sudah dikenal sejak 1000 tahun yang lalu, diawali kedatangan penambang emas dari Cina yang kemudian dilanjutkan pada zaman Hindu dan penambangan lebih intensif pada zaman pendudukan Belanda dan Jepang. Saat ini penambangan masih berlanjut dan Indonesia sendiri memproduksi sekitar $4 \%$ dari produksi emas global.

- Geofisika merupakan salah satu bidang keilmuan yang dapat diaplikasikan untuk eksplorasi bahan tambang dan mineral. Didalamnya terdapat berbagai metode yang memegang peranan penting untuk mendukung keberhasilan eksplorasi emas, salah satunya Metode Geolistrik Resistivitas \& Polarisasi Terinduksi. Metode ini telah terbukti ampuh untuk membuktikan keberadaan deposit emas (Candra et al., 2017; Coggan,1984; Kelly,1975)

\section{Bijih Emas Epitermal}

Istilah epitermal digunakan untuk deposit yang terbentuk pada kedalaman dangkal ( $\pm 2 \mathrm{~km}$ dibawah permukaan) dengan rentang temperatur $150^{\circ}-300^{\circ} \mathrm{C}$ (Berger dan Eimon, 1983). Emas epitermal cenderung memiliki sumber primer lebih khas daripada emas mesotermal, terutama terjadi pada batuan intrusive dan vulkanik dengan kedalaman dangkal pada setting tektonik konvergen. Dua tipe mineralisasi yang khas dari bijih emas epitermal ini dikembangkan berdasarkan 
kontras fluida geokimia. Setiap tipe memiliki karakteristik mineraloginya sendiri dan tanda-tanda alterasi batuan dindingnya (wall rock alteration). Epitermal sulfida rendah terbentuk dari berkurangnya $\mathrm{pH}$ cairan mendekati netral dengan kandungan air meteorik yang besar sedangkan sistem epitermal sulfida tinggi terbentuk dari cairan asam teroksidasi yang dihasilkan dari sistem magmatik-hidrotermal.

\section{Litologi dan alterasi daerah Penelitian}

Lithologi pada daerah prospek didominasi oleh batuan intrusif riodasit, diatrem breksia (phreatomagmatic brecia) dan hidrotermal breksia. Diatrem breksia terbentuk akibat adanya kontak langung antara magma dengan air. Magma yang berada jauh di dalam bumi menerobos keatas melalui struktur seperti patahan, fraktur, maupun shear. Semakin mendekati ke permukaan, magma akan kontak dengan air tanah sehingga terjadi ledakan eksplosif dan terbentuklah batuan beku breksia yang sering disebut sebagai breksia diatrem. Breksia hidrotermal sendiri terbentuk dari hasil dekompresi eksplosif dari gas volatih magma. Eksolusi gas dari magma cair menghasilkan tekanan ekplosif yang meloloskan pada bagian atas dari permukaan magma chamber dan melewati (overlying) batuan sekitarnya.

\section{Metode Resistivitas}

Setiap material yang ada di bumi memiliki karakter tersendiri. Salah satu sifat tersebut adalah kelistrikan. Batuan dan mineral memiliki kemampuan untuk menghantarkan arus maupun menahan arus yang mengalir. Kemampuan suatu bahan untuk menahan arus listrik disebut sebagai resistivitas, sebaliknya kemampuan suatu bahan untuk mengalirkan arus listrik disebut sebagai konduktivitas. Untuk memudahkan dalam menentukan dugaan jenis batuan maupun mineral yang diukur, maka dibuatlah suatu rentang nilai resistivitas maupun konduktivitas.
Tabel 1. Rentang nilai resistivitas beberapa material (Telford et al, 2004)

\begin{tabular}{|cc|}
\hline Material & Resistivity $(\mathbf{\Omega m})$ \\
\hline Air & (Infinity) \\
\hline Pirit & $0.01-100$ \\
\hline Quartz & $500-800,000$ \\
\hline Calcite & $1 \times 10^{12-1} \times 10^{13}$ \\
\hline Rock salt & $30-1 \times 10^{13}$ \\
\hline Granite & $200-100,000$ \\
\hline Andesite & $1.7 \times 10^{2-45} \times 10^{4}$ \\
\hline Basal & $200-100,000$ \\
\hline Limestone & $5000-10,000$ \\
\hline Sandstone & $200-8,000$ \\
\hline Slate & $20-2,000$ \\
\hline Sand & $1-1,000$ \\
\hline Clay & $1-100$ \\
\hline Groundwater & $0.5-300$ \\
\hline Sea water & 0.2 \\
\hline Dry pebbles & $600-10,000$ \\
\hline Alluvium & $10-800$ \\
\hline
\end{tabular}

\section{Metode Polarisasi Terinduksi}

Prinsip pengukuran dari metode IP adalah dengan menginjeksikan aliran listrik kedalam bumi menggunakan elektroda arus dan mengukur beda potensial yang terjadi sesaat setelah arus dimatikan menggunakan elektroda potensial. Pada saat arus dimatikan, idealnya beda potensial akan langsung menjadi nol. Tetapi pada medium atau lapisan tertentu akan menyimpan energi listrik yang bertindak sebagai kapasitor dan baru dilepaskan kembali. Efek inilah yang disebut sebagai Efek Polarisasi. Jadi ketika arus dikirim dan kemudian diputus, beda tegangan tidak langsung menjadi nol namun berangsur-angsur hilang menjadi nol. Efek ini dapat terjadi akibat adanya suatu medium yang mengandung logam.

Polarisasi sendiri diakibatkan oleh dua sumber utama, yaitu polarisasi elektroda dan polarisasi membran. Polarisasi elektroda dapat terjadi karena adanya mineral logam pada batuan. Dengan terdapatnya mineral, maka aliran arus akan terhambat sehingga muatan akan terpolarisasi pada bidang batas. Supaya arus dapat menembus hingga lapisan dalam dan melewati hambatan elektrokimia, dibutuhkan tegangan yang besar (overvoltage). 
Tabel 2. Rentang nilai chargeability (Dentith, 2014)

\begin{tabular}{|c|c|}
\hline Material dan Batuan & Nilai Chargebility $(\mathrm{ms})$ \\
\hline Air tanah & 0 \\
\hline Alluvium & $1-4$ \\
\hline Gravels & $3-9$ \\
\hline Precambrian Vulkanik & $8-20$ \\
\hline Precambrian gneisses & $6-30$ \\
\hline Schist & $5-20$ \\
\hline Batu pasir & $3-12$ \\
\hline Argilik & $3-10$ \\
\hline Kuarsa & $5-12$ \\
\hline $20 \%$ sulfida & $2000-3000$ \\
\hline $8-20 \%$ sulfida & $1000-2000$ \\
\hline $2-8 \%$ sulfida & $500-1000$ \\
\hline Vulkanik tuff & $300-800$ \\
\hline Shale & $50-100$ \\
\hline Granit & $10-50$ \\
\hline Limestone & $10-20$ \\
\hline
\end{tabular}

\section{METODE PENELITIAN}

Metode yang digunakan pada penelitian kali ini adalah geolistrik resistivitas dan IP dengan menggunakan instrumen Zonge International Inc. Pada instrumen ini terdiri dari tiga komponen utama yaitu Transmitter, Switchbox, dan Receiver. Data yang didapatkan adalah nilai resistivitas sekaligus polarisasi induksi. Konfigurasi yang digunakan yaitu Dipole-Dipole baik pada pengambilan data resistivitas maupun polarisasi induksi. Proses akuisisi data lapangan menggunakan 3 buah porous pot sebagai penerima beda potensial dan 13 elektroda sebagai media pengirim arus listrik. Jarak antar tiap elektroda maupun porous pot adalah 50 meter. Dengan demikian akan membuat proses akuisisi data menjadi efektif dan efisien sehingga lebih cepat selesai dan mengurangi anggaran pengeluaran.

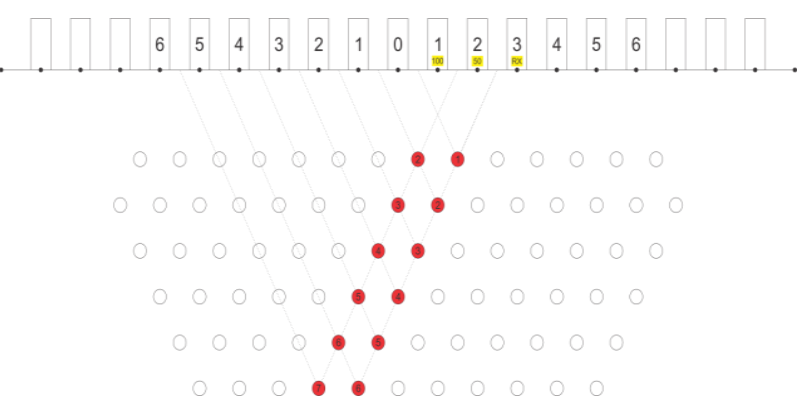

Gambar 1. Teknik pengambilan data dipole-dipole

Berikut ini akan diberikan diagram alir dari penelitian.

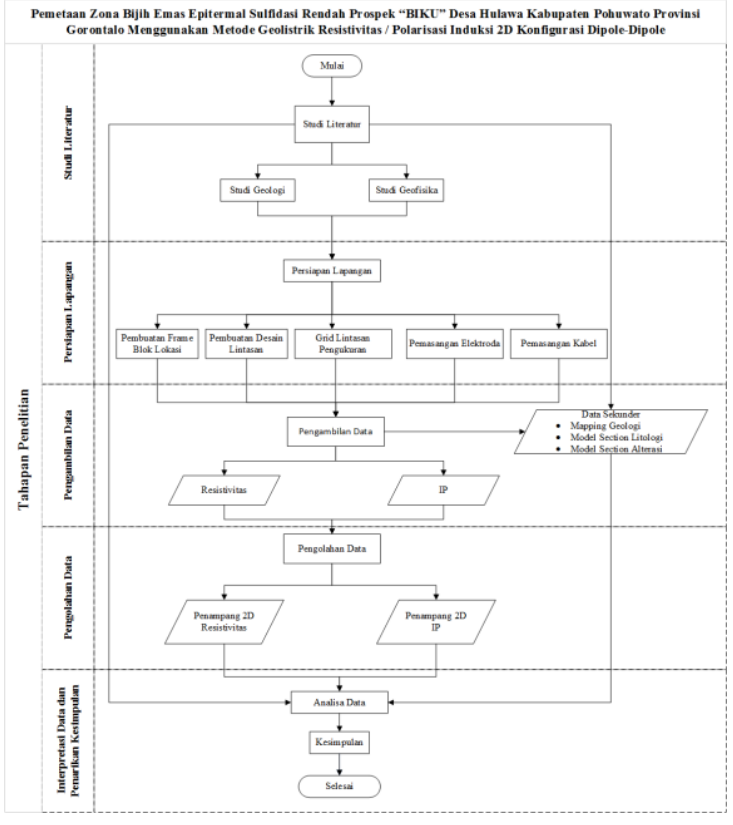

Gambar 2. Diagram alir penelitian

\section{HASIL DAN PEMBAHASAN}

Hasil pengolahan data resistivitas dan polarisasi terinduksi berupa penampang dua dimensi. Proses inversi menggunakan software RES2DINV 4.07. Hasil pengolahan ditampilkan dalam 2 penampang sekaligus, yaitu resistivitas dan chargeability. Resistivitas digunakan untuk mengatahui jenis litologi sedangkan chargebability untuk mengetahui jenis alterasi. Pada masing-masing kedua hasil penampang, diberikan variabel kontrol rentang nilainya. Untuk nilai resistivitas digunakan rentang nilai per $25 \Omega m$ dan untuk nilai chargeability rentang nilai per $1 \mathrm{~ms}$. Dengan memberikan rentang nilai tersebut pada keseluruhan penampang lintasan pengukuran, akan dihasilkan kontras warna yang sama sehingga diharapkan akan lebih mudah dalam melakukan interpretasi.

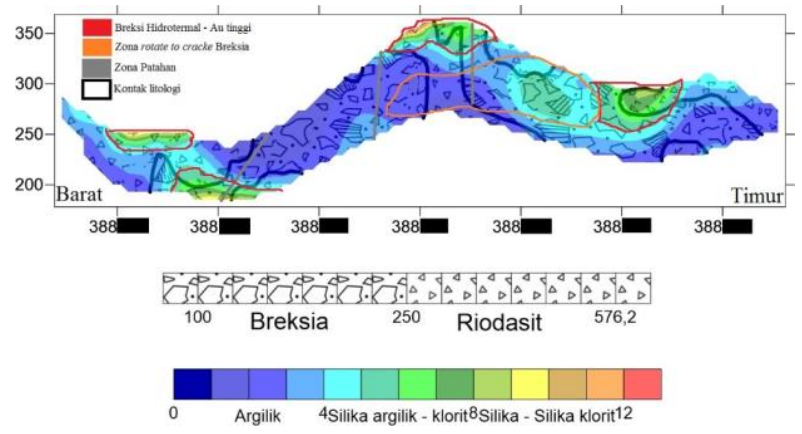

Gambar 3. Hasil overlay kedua metode pada lintasan 1 
Penampang overlay lintasan satu seperti pada memperlihatkan pada lintasan dekat permukaan didapatkan dugaan litologi breksi hidrotermal dengan ada/tidaknya asosiasi bersama litologi intrusif riodasit teralterasi silika-silika klorit. Bagian barat lintasan didapatkan alterasi serupa semakin kedalam menunjukkan nilai chargeability yang cenderung meningkat dengan dugaan litologi breksi hidrotermal berasosiasi dengan litologi intrusif riodasit. Kedua zona ini didinterpretasi sebagai zona dengan kandungan Au yang tinggi pada lintasan ini. Sementara dugaan litologi breksi diatrem dengan alterasi argilik berada pada bagian tengah lintasan cenderung menerus kearah barat.

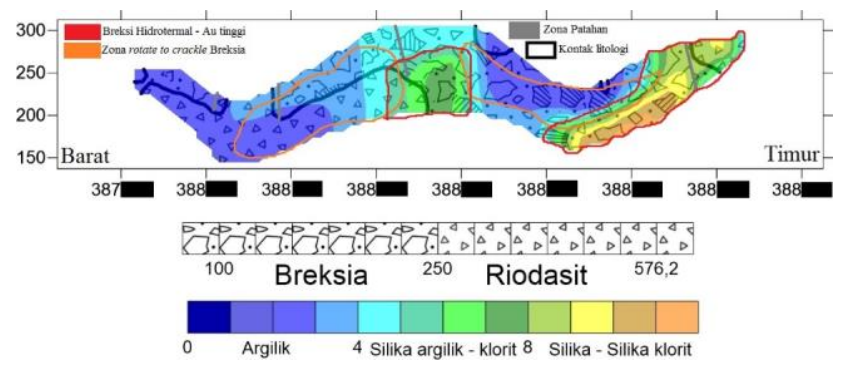

Gambar 4. Hasil overlay kedua metode pada lintasan 2

Penampang lintasan dua memperlihatkan bagian paling barat ke bagian tengah lintasan didominasi oleh dugaan litologi intrusif riodasit yang berasosiasi dengan breksi hidrotermal. Zona ini diinterpretasi sebagai zona rotate to crackle breksia. Hal ini dibuktikan dengan nilai chargeability yang semakin meningkat dengan alterasi silika klorit-silika argilik. Bagian tengah lintasan menunjukkan nilai chargeability yang meningkat terhadap kedalaman diinterpretasi sebagai litologi breksi hidrotermal teralterasi silika argilik-silika klorit. Zona ini diprediksi memiliki kandungan Au yang tinggi. Pada bagian paling timur lintasan didapatkan dugaan litologi breksi hidrotermal berasosiasi dengan intrusif riodasit dengan alterasi yang cenderung meningkat terhadap kedalaman mencapai $12 \mathrm{~ms}$ diinterpretasi sebagai litologi breksi hidrotermal dengan alterasi silika-silika klorit. Pada zona inilah diinterpretasi memiliki kandungan Au yang paling tinggi pada lintasan ini.

\section{PENUTUP}

\section{Kesimpulan}

Berdasarkan hasil pengolahan data dan interpretasi, didapatkan beberapa kesimpulan, diantaranya dugaan litologi breksi memiliki rentang nilai $>100 \Omega \mathrm{m}$ hingga $\leqslant 250 \Omega \mathrm{m}$ sedangkan intrusif riodasit dengan nilai resistivitas $\geqslant 250 \Omega \mathrm{m}$, dugaan litologi diatrem breksi dicirikan dengan alterasi argilik memiliki nilai chargeability antara 2-4 $\mathrm{ms}$, dugaan litologi breksi hidrotermal dengan alterasi silika klorit-silika argilik memiliki nilai chargeability antara 6-12 ms, dugaan litologi intrusif riodasit dengan alterasi argilik- silika argilik memiliki nilai chargeability 4-6 ms.

\section{Ucapan Terimakasih}

Peneliti mengucapkan terima kasih banyak kepada pihak Perusahaan yang telah memberikan fasilitas untuk melaksanakan penelitian ini. Tak lupa pula kepada seluruh kru dan supervisor yang telah membimbing dan mendampingi selama proses pengambilan data.

\section{DAFTAR PUSTAKA}

Allis, R.G. , 1990. Geophysical Anomalies Over Epithermal System. Journal of Geochemical Exploration, 36 (1990) 339-374

Bachri, S., Sukido., dan Ratman, N., 1983. Peta Geologi Lembar Tilamuti Sulawesi. Bandung : Pusat Penelitian dan Pengembangan Geologi.

Caira, N., dan Pearson, D., 1999. The Geology and Metallogeny of Central North Sulawesi, Indonesia. Unpub. Manuscript for PACRIM 1999.

Candra, A., Fadlin, F., Gnr, J.P., 2017. Eksplorasi Geologi Bijih Besi Berdasarkan Data Geolistrik Induksi Polarisasi Daerah Ngolonio Nusa Tenggara Timur. J. Ilmu Kebumian Teknol. Miner. JIK TekMin 1.

Corbett, G. J., 2007, Controls to Low Sulphidation Ephitermal Au-Ag Mineralization, PO Box 282 Willoughby NSW Australia.

Davies, B., 2017. Pani Project : Trap Site Structure and Exploration Implication. Unpub Company Report for PT J Resources Nusantara

Dentith, M., dan Stephen, 2014. Geophysics For The Mineral Exploration Geoscientist. Cambridge University Press

Telford., dan Geldart., 2004. Applied Geophysics Second Edition. USA. Cambridge University Press. 